Instituto Internacional de Investigación y Desarrollo Tecnológico Educativo INDTEC, C.A.

DOI: https://doi.org/10.29394/scientific.issn.2542-2987.2016.1.2.16.274-294

OAI-PMH: http://www.indteca.com/ojs/index.php/Revista Scientific/oai

\title{
Liderazgo del Personal Directivo en el Subsistema de Educación Primaria. U.E. "Dr. Amílcar Fonseca"
}

Autora: Yajaira Esperanza Araujo Araujo Universidad Nacional Experimental "Rafael María Baralt", UNERMB araujoyajairaunica@hotmail.com Trujillo, Venezuela

\section{Resumen}

El propósito de la presente investigación es determinar el liderazgo del personal directivo en el subsistema de educación primaria de la Unidad Educativa "Dr. Amílcar Fonseca" Municipio Candelaria Estado Trujillo. El estudio fue de tipo descriptivo porque permitió profundizar el conocimiento, el saber y la información de la variable planteada: liderazgo, utilizando para ello un diseño de campo por cuanto la información se obtuvo en el mismo sitio de los hechos; es decir, la escuela donde se delimitó la investigación. En relación a la población-muestra se trabajó con 43 docentes que laboran en la institución a los cuales se les aplicó un instrumento tipo cuestionario de alternativas múltiples conformado por 36 ítems y cuya validación la otorgaron tres (03) especialistas los cuales verificaron el cumplimiento de los criterios metodológicos exigidos para tal fin. Mientras que la confiabilidad fue de 0,98 mediante el coeficiente Alpha de Crombach. Los resultados demostraron que en el plantel la gerencia no hace uso de diferentes tipos de liderazgo; llegándose a la conclusión relevante que en la época actual los gerentes educativos deben combinar diferentes paradigmas en su liderazgo.

Palabras clave: liderazgo; gerencia educativa; organización. 


\title{
Leadership Management Personnel in Primary Education Subsystem. EU. "Dr. Amilcar Fonseca"
}

\begin{abstract}
The purpose of this research is to determine the leadership of the management staff in the subsystem of primary education Educational Unit "Dr. Amílcar Fonseca "County Candelaria Trujillo state. The study was descriptive type that helped deepen understanding, knowledge and variable information posed: leadership, using a field design because the information was obtained on the same site the facts; ie, where the school was delimited research. In relation to the sample population worked with 43 teachers working in the institution to which they applied an instrument type questionnaire composed of multiple alternative 36 items and its validation was granted three (03) experts who verified the compliance methodological criteria required for that purpose. While reliability was 0.98 using Cronbach alpha coefficient. The results showed that on campus management does not use different types of leadership; It was concluded that the relevant time current educational managers must combine different paradigms in his leadership.
\end{abstract}

Keywords: leadership; management education; organization. 


\section{Introducción}

Uno de los factores claves en el funcionamiento de las instituciones educativas está presente en su liderazgo, principalmente del personal directivo quienes son piezas claves para el éxito del mismo, sobre todo, en una sociedad que velozmente cambia y se transforma, constituyendo el liderazgo la pieza central de armonía en el intercambio de paradigmas educativos, ya que de este depende la dinámica en los diferentes procesos de interacción institucional. Gran parte del éxito de una organización depende del rol y funciones explicitas que se le atribuyen al personal directivo quienes generan cambios necesarios en el contexto educativo que dirige; los líderes educativos necesitan ejercer con propiedad el liderazgo y la gestión institucional a través de los diferentes ámbitos de acción destacándose entre ellos el clima institucional y de convivencia. De eso se trata esta investigación.

Se busca indagar el liderazgo del personal directivo en el Subsistema de Educación Primaria U.E. "Dr. Amílcar Fonseca" durante sus funciones en el contexto educativo, ya que el liderazgo escolar requiere de un proceso organizado y planificado que favorezca positiva y significativamente el diálogo, el análisis y la reflexión, las cuales tendrán éxito si se definen concretamente las funciones y responsabilidades del liderazgo escolar, la distribución de tareas a todos los integrantes de la comunidad educativa para que se sientan partícipes del proceso, contribuyendo a que el liderazgo genere procesos de acercamiento, el desarrollo de habilidades, conocimientos y actitudes desde lo macro a lo micro provocando un impacto hacia la comunidad de incentivo social. Si no es así, se entorpece la participación de cada uno de los integrantes. 


\section{EI Problema}

\section{Planteamiento y formulación del problema}

Las organizaciones educativas deben repotenciarse a partir de las exigencias de la sociedad actual, donde se promueven cambios, reformas y nuevos modelos de interacción para que las instituciones educativas propicien relaciones de liderazgo con un norte definido. En este contexto de ideas, una de las características que exige las innovaciones contemporáneas en materia educativa está en el liderazgo como cualidad para hacer que los actores que convergen en las organizaciones mantengan una interacción basada en la armonía y el entendimiento.

En el mundo globalizado, la calidad de la educación constituye una preocupación para los países que convergen en la Organización de las Naciones Unidas para la Educación, la Ciencia y la Cultura (2008) UNESCO. En correspondencia con lo anterior, las políticas educativas a nivel mundial cada día exigen la consolidación de liderazgos de los directivos que asumen la responsabilidad de conducir la operatividad del proceso escolar. Específicamente la gestión educativa a finales del siglo XX y principios del siglo XXI se ha visto afectada por variables internas y externas que impulsan cambios significativos en las instituciones educativas; tal apreciación se corresponde con el análisis del documento de gestión escolar perteneciente a los organismos internacionales: Banco Internacional de Desarrollo - Banco Mundial.

En el mismo orden de ideas es de resaltar que la calidad de la educación está estrechamente ligada al liderazgo del gerente organizacional, así lo señala Chiavenato (2006:81), quien hace énfasis que "el liderazgo induce a la consolidación de las relaciones interpersonales". En este escenario se reconoce que una de las preocupaciones latentes que se asume en la época contemporánea es la conducción de las instituciones educativas, señalando 
que un liderazgo proactivo, transformador, sensibilizador es prioridad entre los actores que convergen en las instituciones educativas.

Bajo la perspectiva señalada, se reconoce que en el contexto de las organizaciones educativas, el liderazgo constituye una pieza fundamental para que se consoliden las relaciones interpersonales de los colaboradores que asumen funciones, tareas, y actividades propias del proceso de planificación educativa. En éste escenario las relaciones interpersonales para González (2008:93) "representan presentan diferencia de criterios que hacen que existan, conflictos, desavenencias, enfrentamientos; que ponen en riesgo la operatividad proactiva de la organización como ente social que favorece la comunicación afectiva y efectiva de los colaboradores". Por lo que se hace necesario que el gerente educativo ejerza su liderazgo de la forma más efectiva contribuyendo así a una comunicación efectiva entre el personal.

Para precisar, la percepción del comportamiento humano Chiavenato (2006) sostiene que las relaciones interpersonales, están dadas por el continuo desencadenamiento que produce el desarrollo del potencial que presenta cada ser humano para convivir con su semejante. De tal manera que corresponde al líder desarrollar actitudes enmarcadas en un liderazgo de impacto que favorezca cambios, innovaciones y nuevos paradigmas que busquen hacer de las instituciones educativas, centros de aprendizaje recíprocos en donde se aprenda el saber que implica la cotidianidad de la vida.

En consecuencia, la percepción que establecen las teorías organizacionales sobre el liderazgo de los directivos de instituciones públicas y privadas responde a la necesidad de que los actores involucrados en la organización consoliden una visión convincente que radique en las relaciones interpersonales. De allí pues que la debilidad que representa las relaciones interpersonales debe ser motivo de preocupación de la estructura jerárquica organizacional donde se ubica el liderazgo directivo. Sobre todo, cuando en 
muchos casos notamos que las directrices son emitidas centralizadamente, ignorando las necesidades particulares de cada institución.

En el marco del análisis del liderazgo de los directores que actúan en el sector educativo en Venezuela, cabe referir a Robbins (2004) para quien reconoce que ser líder en las instituciones, en este sentido en el contexto escolar, es garantizar la proactividad, sinergia y empatía para hacer de la escuela el centro de convergencia de ideas, criterios y opiniones que conduzcan al entendimiento humano para lograr con ello la meta que representa la visión y misión de las instituciones educativas.

Es importante acotar que según los informes de gestión educativa del Ministerio del Poder Popular para la Educación (2007) la ausencia de un liderazgo en los directivos constituye una preocupación latente para la gerencia escolar en el país; ya que por lo general debe ser el centro operativo que, a través de la ayuda, colaboración, participación de los involucrados en el proceso escolar se consolide la calidad educativa.

Lo expresado en el párrafo anterior, da origen a promover e impulsar investigaciones, estudios, mesas de trabajo donde se reflexione sobre la necesidad apremiante de alcanzar liderazgo en los directivos que favorezcan las relaciones interpersonales para que con la ayuda de los colaboradores se tenga la visión compartida de hacer de la escuela una organización que responda al alto desempeño con la toma de decisión compartida, comunicación efectiva, aprendizaje continuo y procesos de evaluación que permitan la realimentación del cumplimiento de rol y funciones.

Al transferir la contextualización de la problemática que representa la ausencia de liderazgo de los directivos en las organizaciones educativas para consolidar las relaciones interpersonales al Estado Trujillo Venezuela, la Zona Educativa-Dirección de Educación Regional en su Informe de Gestión del Año (2009-2010) reconoce que las instituciones escolares presentan debilidad en la conducción gerencial. Al respecto Zuleta (2006), catedrático de la 
Universidad de los Andes en el Núcleo Trujillo señala que: "una de las variables que más afecta la gerencia educativa está en la falta de relaciones interpersonales de los docentes que hacen vida activa en los centros educativos".

Específicamente en la U.E. Dr. Amílcar Fonseca. Estado Trujillo. Venezuela. Municipio Candelaria, en la técnica de observación aplicada a través de la interacción comunicacional con los docentes, y de los análisis reflexivos efectuados en los círculos de acción docente permitieron inferir que en el plantel, el liderazgo del directivo presenta debilidades. Se percibe discusiones, opiniones encontradas, deficiente comunicación, ausencia de disposición para participar, apoyar y compartir de manera responsable las actividades que se ejecuten en la institución, ésta realidad se puede mejorar cuando exista un liderazgo consolidado de parte de los directivos convirtiendo su actuación en un modelo a copiar que oriente las relaciones interpersonales hacia metas y objetivos organizacionales.

Ante lo planteado se propone como objetivo: Determinar el liderazgo Proactivo y Transformador del personal directivo en el subsistema de educación primaria de la Unidad Educativa "Dr. Amílcar Fonseca" Municipio Candelaria Estado Trujillo. Estudio que requiere ser realizado debido a la relevancia del liderazgo en las relaciones interpersonales, pues las mismas constituyen una problemática que debe ser superada para generar un clima de trabajo en equipo que lleve a optimizar la calidad educativa.

\section{Fundamento Teórico}

\subsection{Liderazgo}

El liderazgo surge en el Siglo XX con la finalidad de establecer características o rasgos que diferencian un líder del otro. Diversas son las concepciones que existen sobre liderazgo, por lo que cabe referir a Robbins (2009:437), para quien el liderazgo es "la influencia interpersonal ejercida en 
una situación, dirigida a través del proceso de comunicación humana para la consecuencia de uno o diversos objetivos específicos". Se puede decir que el liderazgo es el proceso de dirigir e influir en las actividades laborales de los colaboradores que comparten en la organización.

Es por ello, que el liderazgo ha constituido desde hace mucho tiempo una variable interesante de investigación, puesto que el mismo ha ocupado una parte central de comprensión del comportamiento del grupo. En tal sentido, el liderazgo debe centrarse en el cambio y la innovación. Por cuanto el liderazgo es visto como la capacidad de influir sobre otros mediante el desencadenamiento del poder y el potencial de las personas y las organizaciones para la obtención de un bien mayor, para lograr resultados valiosos a la vez que se actúa con respeto, cuidado y justicia.

En correspondencia con lo señalado Blanchard (2007: XVII) define al liderazgo como "la capacidad de influir sobre otros mediante el desencadenamiento del poder y el potencial de las personas y las organizaciones para la obtención del bien mayor". Tiene como fin contribuir a la transformación de sus seguidores llevándolos a realizar actuaciones de mayores exigencias que eran capaces de considerar como posibles. En el mismo orden de ideas se considera que el liderazgo es eficaz en las personas cuando comienzan con una mirada así mismo; quien se es, con que se identifica uno y como se toma la iniciativa cuando no se está en una posición de poder.

Cabe destacar que el liderazgo se caracteriza por impulsar la movilización de otros y hacen que las personas se unan en torno a una visión compartida, puesto que esta visión representa una guía para las decisiones cotidianas, de manera que los individuos apunten hacia el mismo objetivo y no entablen entre sí un diálogo de sordos. En tal sentido, el gerente educativo debe ejecutar su liderazgo de forma efectiva, por ser el líder quien tiene a su cargo la institución. 
De acuerdo con Blanchard (2007), el líder es cualquier persona que pueda darle el apoyo y la dirección que necesita lograr su meta. Enfocando nuestro planteamiento al liderazgo en la educación, Martín y Muñoz (2012: 63), indican que "la calidad del liderazgo del directivo influye directamente sobre la capacidad de los centros para mejorar la enseñanza y el aprendizaje". En tal sentido, se puede decir que el directivo como líder debe tener la capacidad de dirigir e identificar las actividades laborales de los miembros de la institución, específicamente en la escuela.

En cuanto al liderazgo que debe desarrollarse en la escuela los directivos deben entender que hoy día se debe propiciar el liderazgo de alto desempeño para lo cual se debe poseer cualidades de líder proactivo, transformador y sensibilizador. De esta manera se precisa entonces que el liderazgo de hoy día en las instituciones educativas debe basarse en el poder compartido y la alta participación de la comunidad educativa, logrando con ello que exista la convivencia, interacción, comprensión, el respeto, la solidaridad y ayuda para consolidar a la escuela como centro operativo de su filosofía institucional.

Según este análisis podemos señalar la existencia diferentes tipos de liderazgo, y utilizaremos para ello las características de liderazgo de Robbins (2004:514) quien identifica tres tipos de liderazgo: liderazgo proactivo, transformador y sensibilizador. De los cuales para efecto del estudio se abordan los dos primeros.

3.1.1. Los Lideres Proactivos: No son dominados, seleccionados 0 asignados formalmente, sino por el contrario son aceptados y seguidos, de este modo el liderazgo proactivo es quien establece metas, pero al hacerlo toma en cuenta las condiciones existentes una vez determinado lo que su grupo puede hacer y ser. Es así como reconoce las oposiciones y las presiones accidentales donde existe una atención mayor al comportamiento adaptativo del carácter organizacional. Facilita la visión a mediano y largo plazo. Así 
mismo es capaz de mover a otros compañeros para trabajar a nivel de equipo y así evitar el exceso de concentración en la figura del director general, esta buena gestión de equipo enfocada hacia el objetivo común.

Trata de hacerse entender, no de hacerse temer, de implementar mejores estrategias y dar respuestas inmediatas e incluso anticiparse a las cosas. Cabe destacar que un líder proactivo debe tener iniciativa, estar a la cabeza de un equipo o proyecto, siempre con un paso delante de los posibles puntos de oportunidad no esperar a que te digan que hacer, preguntar que sigue, esperar a ver qué falla. En esa misma dirección un liderazgo pone en práctica sus destrezas, y conocimientos, saber motivar, comprometer, inspirar, escuchar y hacer sentir a las personas como parte importante, compartiendo su pasión y dedicación en pro del grupo, haciendo que todos sus miembros se sientan plenamente identificados con los objetivos a cumplir.

3.1.2. Liderazgo transformador; desde la perspectiva de Carrera (2002:139), "No sólo es jerarquía, sino que forma parte de un proceso de aprendizaje e intercambio con sus seguidores creando un sentido del deber dentro de las organizaciones fomentando una nueva forma de manejar los problemas". El líder transformador inspira el éxito de una organización y su excelencia se mide por su capacidad de transformar los problemas en oportunidades. En correspondencia con lo anterior, Carrera (2002:18) establece que" todo liderazgo transformador se caracteriza por ser innovador, creativo y comprometido".

En síntesis, la cualidad del liderazgo transformador se enmarca en generar compromisos que han de producir el logro de objetivos y metas, propios de la organización al establecer actitudes que generan el reto en los colaboradores para el trabajo mancomunado en función de la institución. De igual manera es de resaltar que estar comprometido con la institución educativa, es desarrollar el sentido de pertenencia para hacer que los 
colaboradores aprecien en él la identidad con las funciones que se cumplen, asumiéndolas con responsabilidad y dedicación.

3.1.3. Liderazgo sensibilizador. Permite que en los miembros de la organización exista un estímulo de percepción que comprenda mejor su propio comportamiento y el de otros seres humanos, capitalizando el recurso humano con que cuenta a través del desarrollo del conocimiento, habilidades y actividades para gestionar adecuadamente las personas.

De esta manera el líder sensibilizador debe enfocarse en los sentimientos, emociones, conductas e interacciones de los individuos, para el, no es suficiente informar, sino que necesita compartir sus expectativas, anhelos, sus percepciones, sentimientos y experiencias, lo cual incluye no sólo expectativas del futuro sino también expresar con sinceridad sus temores e incertidumbres.

3.1.4. El liderazgo mediador; se caracteriza por el entendimiento negociable que hace el líder capaz de atravesar los conflictos por lo tanto este tipo de líder debe hacer que las partes vuelvan a escucharse y a comunicarse sus respectivos intereses, prestando una asistencia más directa a las partes para encontrar una solución aceptable para así incorporar sus propuestas como parte de la solución de tal modo que las partes la sientan como propias. De estas consideraciones éste tipo de líder debe solucionar conflictos no crearlos, debe ser capaz de entrar en cualquier entorno por hostil que parezca convirtiendo los conflictos serios en oportunidades gratificantes para la colaboración y la innovación.

Es por ello que debe tener visión integral; tomar en cuenta a todas las partes del conflicto con toda su complejidad, identificando todos los elementos significativos relacionados con la situación del conflicto comprendiendo así las relaciones entre dichos elementos, debe aplicar todos los recursos mentales, emocionales y espirituales para presenciar el conflicto del cual ahora forma parte. 
En relación al líder tolerante, establece que la tolerancia hace referencia a la cualidad del liderazgo sensibilizador para despertar el interés de los actores organizacionales, a trabajar en conjunto, en función de la organización como ente social que requiere del consenso individual y colectivo de los actores que hacen vida activa en la organización. En éste orden de ideas se precisa que ser tolerante es desarrollar un liderazgo que sensibilice a todos y todas hacia el respeto, la comprensión, el compañerismo por hacer de cada actividad organizacional una experiencia significativa, útil a la vida, tolerar las cualidades positivas y negativas de los semejantes.

\section{Metodología}

El estudio fue de tipo descriptivo, que según Hernández, Fernández y Baptista (2007: 60) "se busca especificar propiedades importantes de personas, grupos, comunidades o cualquier otro fenómeno que sea sometido a análisis". El mismo permitió profundizar el conocimiento, el saber y la información de la variable planteada: liderazgo. Utilizando para ello un diseño de campo, por cuanto la información se obtuvo en el mismo sitio de los hechos; es decir, la escuela donde se delimitó la investigación.

Con relación a la población, Hernández y otros (2007: 60), manifiestan que "la población es el conjunto de todos los casos que concuerda con una serie de especificaciones". Tomando en cuenta que la población la constituyen 43 docentes que laboran en la institución, la cual por ser fácil de acceso, no se hizo necesario establecer una muestra. Para recabar la información se construyó un cuestionario como instrumento, con varias alternativas, conformado por 12 ítems y validado por tres (03) especialistas los cuales verificaron el cumplimiento de los criterios metodológicos exigidos para tal fin. Mientras que la confiabilidad fue de 0,98 mediante el coeficiente Alpha de Crombach, que por estar cerca de 1 se consideró altamente confiable para su aplicación. 


\section{Resultados y Análisis:}

\subsection{Variable: Liderazgo}

Dimensión: Proactividad del personal directivo desarrollado en el subsistema de educación primaria.

Tabla № 1. Liderazgo Proactivo.

\begin{tabular}{|c|c|c|c|c|c|c|c|}
\hline IIEss & & $\mathbf{s}$ & Av & $\mathbf{o}$ & Rv & $\mathbf{N}$ & TOTNL \\
\hline \multirow{2}{*}{ 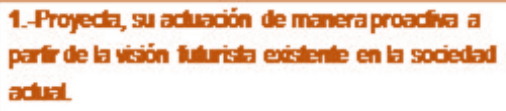 } & $\mathbf{F}$ & - & - & 5 & $\mathbf{2 8}$ & 10 & 43 \\
\hline & $\mathbf{x}$ & - & - & $11,6 \%$ & $\infty, 1 \%$ & $23,2 \times$ & $100 \%$ \\
\hline \multirow{2}{*}{$\begin{array}{l}\text { 2-Planilica, a thiro actidades, acciones y } \\
\text { estrategizs que projecten la organización. }\end{array}$} & $\mathbf{F}$ & - & 6 & 8 & 20 & 9 & 43 \\
\hline & $\mathbf{x}$ & & $13,9 \%$ & $18,6 \%$ & $46,5 \%$ & 20,90 & $100 \%$ \\
\hline \multirow{2}{*}{$\begin{array}{l}\text { 3.Adtuaciones de empitiz para que surs } \\
\text { coliboradores le ajuden al logro de metiss } \\
\text { inclitucioniles. }\end{array}$} & $\mathbf{F}$ & - & - & 3 & 22 & 18 & 43 \\
\hline & $\mathbf{x}$ & - & - & $6,97 \%$ & $51,2 \pi$ & $41,4 \%$ & $100 x$ \\
\hline \multirow{2}{*}{ 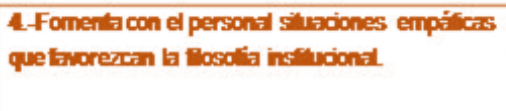 } & $\mathbf{F}$ & - & 9 & 10 & 11 & 13 & 43 \\
\hline & $\mathbf{5}$ & - & $20,9 \%$ & $23,6 \%$ & $25,6 \%$ & 30,2 & $100 \%$ \\
\hline \multirow{2}{*}{ 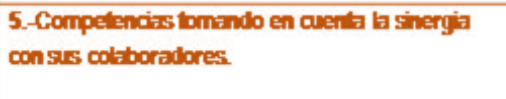 } & $\mathbf{F}$ & - & 3 & 7 & 15 & 18 & 43 \\
\hline & $\mathbf{x}$ & - & $7 \%$ & $16,3 \%$ & $34,9 \%$ & $41,9 \%$ & $100 \%$ \\
\hline \multirow{2}{*}{$\begin{array}{l}\text { 6.-Trabajacon honestidad, compromiso y toma de } \\
\text { decisiones comparidis }\end{array}$} & $\mathbf{F}$ & - & - & 2 & 22 & 19 & 43 \\
\hline & $\mathbf{x}$ & - & - & $4,7 \%$ & $51,2 \%$ & $44,1 \times$ & $100 \%$ \\
\hline
\end{tabular}

Fuente: Cuantificación de las respuestas emitidas con la aplicación del instrumento diseñado (Araujo, 2011).

Al interpretar los resultados obtenidos de la dimensión liderazgo proactivo se tiene que, el $65,1 \%$ de los docentes encuestados señalaron que "rara vez" proyectan, su actuación de manera proactiva a partir de la visión futurista existente en la sociedad actual, el $23,2 \%$ "nunca" y solo el $11,6 \%$ "ocasionalmente". En este sentido Carrera (2002) afirma que el liderazgo futurista es aquel que planifica a futuro su actuación, conduciendo la gerencia de su organización hacia la calidad. Con respecto al ítem № 2 se verificó que el 46,5\% "rara vez" planifican a futuro actividades, acciones y estrategias que proyectan la organización, el 20,9\% "nunca", el 18,6\% "ocasionalmente" y solo 
el 13,9\% "algunas veces". En éste sentido Cornejo (2000) ratifica que el líder futurista busca ser proactivo y mantiene la pertinencia en todos los niveles educativos dirigiendo la mirada hacia el futuro.

Con respecto al ítem № 3 las respuestas de los informantes se enmarcan en el 51,2\% "rara vez" considera que la actuación del director es de empatía para que sus colaboradores le ayuden al logro de metas institucionales, el 41,9\% "nunca" y solo el 6,97\% "ocasionalmente". En este escenario Chiavenato (2006) sostiene que la empatía hace que el director en su liderazgo pueda ubicarse en el lugar de sus colaboradores, entendiéndolos para darles atención individualizada.

En relación al ítem № 4 los resultados indican que el 30,23\% "nunca" el personal directivo fomenta con su equipo docente situaciones empáticas que favorezcan la filosofía institucional, el 25,5\% "rara vez", el 23,6\% "ocasionalmente" y solo el 20,9\% "algunas veces". Al respecto el autor antes citado ratifica que el liderazgo empático tiene presente la identificación con su equipo para fomentar trabajo en equipo y sentido de pertenencia con su organización.

Específicamente el ítem № 5, demostró que el 41,9\% "nunca" el personal directivo desarrolla competencias en la organización; tomando en cuenta la sinergia con sus colaboradores, el 34,9\% "rara vez", el 16,3\% "ocasionalmente" y solo el 6,2\% "algunas veces". En este sentido Sánchez (2003) considera que el líder sinérgico es aquel que hace que los objetivos logrados por la organización o sistema son alcanzados con creces considerando solo un resultado obtenido en conjunto mayor.

En virtud de lo anterior se precisa que el ítem № 6 demostró que el $51,2 \%$ "rara vez" el director en su liderazgo trabaja con honestidad, compromiso y toma de decisiones compartidas, el $44,2 \%$ "nunca" y solo el $4,7 \%$ "ocasionalmente". Tal como lo señala Chiavenato (2006) el líder 
sinérgico debe demostrar con su actitud positiva, es decir proactividad la aplicación de valores para crear unidad social

\subsection{Dimensión Transformador.}

Tabla № 2. Liderazgo Transformador.

\begin{tabular}{|c|c|c|c|c|c|c|c|}
\hline IIEs & & $\mathbf{s}$ & Av & D & $\mathbf{R v}$ & $\boldsymbol{n}$ & TDTN \\
\hline \multirow{2}{*}{ 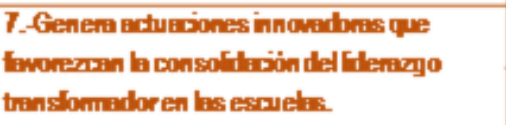 } & $\mathbf{F}$ & - & - & 4 & 10 & $\mathbf{z}$ & B \\
\hline & $\mathbf{z}$ & - & - & $9,3 \times$ & $\mathbf{B}, 3 \mathbf{3}$ & $67,6 x$ & $100 \%$ \\
\hline \multirow{2}{*}{$\begin{array}{l}\text { 8.-Ohece ooportunitades paralognarb pro- } \\
\text { activilad entre el gnupode sus colabonahores. }\end{array}$} & $\mathbf{F}$ & - & - & 1 & 12 & 30 & B \\
\hline & $\mathbf{z}$ & & - & $2,3 \%$ & $27,9 x$ & 정,8\% & $100 \%$ \\
\hline \multirow{2}{*}{ 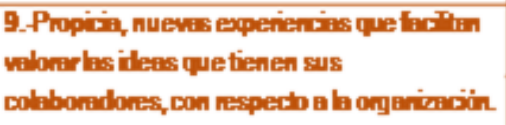 } & $\mathbf{F}$ & - & 4 & 11 & 13 & 15 & B \\
\hline & $\mathbf{z}$ & - & $9,3 \times$ & $5,6 x$ & $30,2 x$ & $34,9 \%$ & $100 \%$ \\
\hline \multirow{2}{*}{ 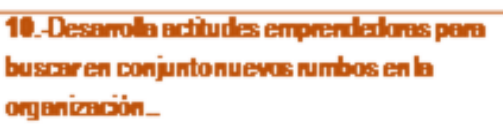 } & $\mathbf{F}$ & - & - & 3 & 11 & $\mathbf{z}$ & B \\
\hline & $\mathbf{z}$ & - & - & $7 \times$ & $8,6 \times$ & 67,4 & $100 \%$ \\
\hline \multirow{2}{*}{ 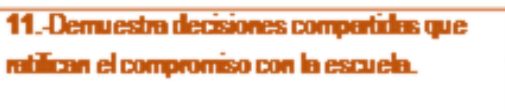 } & $\mathbf{F}$ & - & 5 & $\mathbf{9}$ & 12 & 17 & B \\
\hline & $\mathbf{z}$ & - & $11,6 \times 6$ & $20,9 \%$ & $27,9 x$ & $39,5 \%$ & $100 \%$ \\
\hline \multirow{2}{*}{ 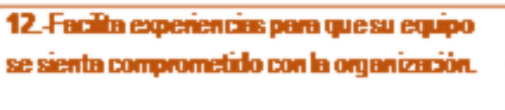 } & $\mathbf{F}$ & - & 5 & 10 & 12 & 16 & B \\
\hline & $\mathbf{z}$ & - & $11,6 \times 6$ & 23,3\% & $27,9 x$ & $37,2 \times 6$ & $100 \%$ \\
\hline
\end{tabular}

Fuente: Cuantificación de las respuestas emitidas con la aplicación del instrumento diseñado (Araujo, 2011)

Al analizar los resultados obtenidos del ítem № 7, del indicador liderazgo transformador se tiene que el $67,4 \%$ "nunca" su actuación innovadora favorece la consolidación del liderazgo transformador en la escuela, el 23,35\% "rara vez" y solo el 9,3\% "ocasionalmente". En tal sentido Robbins (2004) considera que el líder innovador con su forma de actuar encaja en la conducta de los demás provocando el cambio, reformas y nuevos paradigmas. 
Con relación al ítem N N 8 se comprobó que el 69,8\% "nunca" el personal directivo ofrece oportunidades para lograr la proactividad entre el grupo de sus colaboradores, el $27,9 \%$ "rara vez" y solo el $2,3 \%$ "ocasionalmente". Al respecto Robbins (2004) certifica que el liderazgo de un director es capaz de mover a otros compañeros para trabajar en equipo enfocado hacia un objetivo común y así evitar el exceso de concentración en la figura del director general.

Con respecto al ítem № 9 se verificó que el 34,9\% "nunca" propicia, nuevas experiencias que faciliten valorar las ideas que tienen sus colaboradores con respecto a la organización, el 30,2\% "rara vez", el 25,6\% "ocasionalmente" y solo el 9,3\% "algunas veces". En este escenario Cornejo (2006) sostiene que la esencia del líder creativo está en ser una persona dada a lo nuevo, ser volátil en las ideas y abre nuevos espacios a la relación entre los seres humanos.

En relación con el ítem № 10 certifica que el 67\% la parte directiva en su liderazgo "nunca" desarrolla actitudes emprendedoras para buscar en conjunto nuevos rumbos en la organización, el 25,6\% "rara vez" y solo el $7 \%$ "ocasionalmente". En éste sentido el autor antes señalado afirma que el líder creativo es emprendedor y aprendiz de por vida, debe saber estimular el pensamiento crítico y constructivo, poseer habilidad analítica que permita reconocer y seleccionar cuales ideas son convenientes de perseguir y elaborar y cuáles no.

Específicamente el ítem № 11 demostró que el 39,5\% "nunca" el personal directivo demuestra decisiones compartidas que ratifican el compromiso con la escuela, el 27,9\% "rara vez", el 20,9\% "ocasionalmente" y solo el 11,6\% "algunas veces". En este sentido Blanchard (2007) sostiene que el líder comprometido es aquel que manifiesta en sus decisiones el compromiso que tiene con la organización y con su equipo de trabajo.

En virtud de lo anterior se precisa que el ítem № 12 demostró que 37,2\% "nunca" el director en su liderazgo facilita experiencias vivenciales para que su 
equipo se sienta comprometido con la organización, el 27,0\% "rara vez", el $23,5 \%$ "ocasionalmente" y solo el $11,2 \%$ "algunas veces". Tal como lo señala Blanchard (2007), el líder comprometido es el que desarrolla el sentido de pertenencia para hacer que los colaboradores aprecien en él la identidad con las funciones que se cumplen.

\section{A manera de Conclusión}

Al realizar el análisis del liderazgo Proactivo y Transformador del personal directivo en el subsistema de educación primaria de la Unidad Educativa "Dr. Amílcar Fonseca" Municipio Candelaria Estado Trujillo, se puede decir que ocasional mente, rara vez o nunca el directivo asume estos tipos de liderazgo, lo que lleva a la investigadora a reflexionar sobre los resultados y, plantear a manera de cierre lo siguiente.

A partir de los resultados alcanzados se reconoce que el personal directivo de la escuela de la U.E. "Dr. Amílcar Fonseca" no está ganado hacia la proactividad que señalan los autores consultados, contrastándose que no existe total correspondencia entre el deber ser y la realidad que presenta la institución. Por otro lado, se nota en la organización que el liderazgo del director sigue enmarcado en esquemas tradicionales es decir liderazgos autocráticos, democráticos, laissez-faire ya superados por las exigencias de la época contemporánea.

A partir de las consideraciones anteriores es pertinente analizar desde la postura de la discusión de resultados que los cambios, reformas promovidos en el sector educativo exigen al personal directivo enmarcar su liderazgo en la proactividad, significando con ello su disposición de garantizar que, a través de su gestión gerencial, la institución educativa preste el mejor servicio en la formación académica del niño, niña y adolescente.

El liderazgo proactivo es necesario que se lleve a cabo en las instituciones educativas, pues le permite al gerente conducir la organización 
de manera eficaz y eficiente, a la vez que facilita la visión de interactuar con los equipos colaboradores para desarrollar en ellos su sensibilidad con la institución. En este contexto el liderazgo proactivo es futurista, empático y sinérgico, la visión futurista implica estar ganado hasta los cambios que día a día exige la sociedad actual, la empatía es una cualidad que permite al gerente ser solidario, comprensivo y así ganar voluntades para la excelencia organizacional y finalmente la sinergia facilita la proactividad del líder para hacer que la actitud sea positiva en el plantel alcanzando metas y objetivos propuestos.

En cuanto a las respuestas de los informantes sobre el liderazgo transformador, en su mayoría de las veces nunca es asumido por el personal directivo, situación ésta que lleva a la organización escolar, en donde se delimitó el estudio, seguir enmarcada en la actuación de un líder tradicional, con poca disposición hacia los nuevos paradigmas; en contraposición con las exigencias organizacionales que se corresponden con reformas cambios propuestos por el Ministerio de Educación.

Con respecto a la cualidad de ser creativo los resultados demostraron que el liderazgo del personal directivo de la institución no responde a ésta característica, por lo general existe poca disposición de aplicar la creatividad como fortaleza que tiene el liderazgo del director para la conducción organizacional por otro lado es de resaltar que ser líder creativo involucra ser emprendedor, romper con el pensamiento convencional; situación que no se evidencia en el plantel con la actuación del líder gerencial.

Específicamente, la medición cuantitativa que se hizo del indicador liderazgo transformador comprometido permite afirmar que ésta cualidad no está presente en el liderazgo que asume el personal directivo de la institución donde se cumplió este estudio, lo que significa que deben asumirse posturas de liderazgo que permitan ratificar el compromiso institucional. Desde la perspectiva epistemológica el liderazgo comprometido como característica del 
líder transformador ratifica el sentido de pertinencia que se tiene con la organización; situación ésta que no está presente en la U.E."Dr. Amílcar Fonseca".

Desde los señalamientos realizados, producto del estudio, se hace necesario sugerir: talleres de formación, actualización y de acción que lleve a los gerentes educativos a conocer en profundidad su labor de gerente, de liderazgo que debe estar a la par de las exigencias del contexto que hoy se requieren. De igual manera, realizar mesas de trabajo con el colectivo institucional, para intercambiar aspectos necesarios a considerar para mejorar a favor de una educación de calidad.

En tal sentido, el Directivo como gerente educativo, debe ser un líder transformador y proactivo, dispuesto a escuchar a la gente, al aprender a aprender, innovador, creativo, planificador estratégico, capaz de fomentar el trabajo en equipo hacia una mayor efectividad y productividad del trabajo. Capaz de generar un clima armonioso, donde las relaciones entre el personal sean óptimas en la medida que da respuesta a las exigencias educativas y con ello una educación de calidad.

\section{Referencias}

Avalino, C. (2007). El líder como ente transformador de las organizaciones. (2da. Ed.). Venezuela: Salesiana.

Blanchard, K. (2007). Liderazgo al más alto nivel: cómo crear y dirigir organizaciones de alto desempeño. Bogotá: Norma.

Carrera, B. (2002). Proyección futurista de los líderes organizacionales. (2da. Ed.). Colombia: Excelencia.

Chiavenato, I. (2006). Administración: Teoría, proceso y práctica. Colombia: McGraw-Hill Interamericana.

Cornejo, M. (2000). Estrategias para triunfar. México: Grad. 
González, C. (2008). Principios básicos de la comunicación. Desarrollo de la comunicación. Teoría de la comunicación. México: Trillas.

Hernández, R., Fernández, C.; y Baptista, P. (2007). Metodología de la investigación. México: McGraw-Hill.

Lanz, R. (2009). Interacción de los actores que intervienen en el proceso escolar. Caracas: Episteme.

Martín, M. y Muñoz, Y. (2012). Liderazgo y desarrollo profesional. En El liderazgo educativo: proyectos de éxito escolar. Serie: Aula Permanente. España: Ministerio de Educación, Subdirección General de Documentación y publicaciones, D.L.

Ministerio del Poder Popular para la Educación (2007). Diseño Curricular del Sistema Educativo Bolivariano. Venezuela: CENAMEC.

Ortiz (2005). El liderazgo basado en la empatía y la proactividad; para el logro institucional. Venezuela: Panapo.

Robbins, S. (2004). Comportamiento Organizacional. (10ma. Ed). México: Pearson Educación.

Organización de las Naciones Unidas para la Educación, la Ciencia y la Cultura, UNESCO (2008). Informe presentado ante la cumbre Iberoamericana. Material mimeografiado. 


\section{Yajaira Esperanza Araujo Araujo \\ e-mail: araujoyajairaunica@hotmail.com}

Nacida en Timotes. Estado Mérida. Cursa estudio de

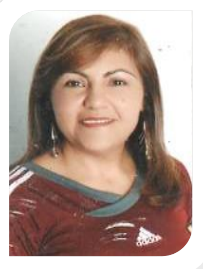

Doctorado en Ciencias de la Educación en la Universidad Nacional Experimental Rafael María Baralt (UNERMB) Estado Trujillo. Magister Scientiarum en Administración de la Educación Básica Universidad Nacional Experimental Rafael María Baralt (UNERMB), Estado Trujillo. Licenciada en Educación Integral Universidad Cecilio Acosta, Valera Estado Trujillo. Técnico Superior Universitario en Educación Preescolar Instituto Universitario de Tecnología Mario Briseño Iragorri, Estado Trujillo. Técnico Medio Mención Administración de Personal Liceo Pedro García Leal, Estado Trujillo. Actualmente se desempeña como Coordinadora Pedagógica en el Núcleo Escolar Rural № 196 Estado Mérida desde el 2013. Se desempeñó durante catorce años de servicio como: Docente de Aula, Coordinador Municipal, y Supervisora de Educación en el Municipio MirandaEstado Mérida. Actualmente es miembro del Colectivo de Danza de la Zona Educativa № 14 del Estado Mérida y del Centro Local de Investigación y Formación Permanente en el Municipio Miranda- Mérida.

Con participación en 9 Congresos Pedagógicos: Municipales, Estadales y Nacionales, 2 Internacionales y más de 20 Jornadas de Formación SocioEducativas, de igual forma ha sido jurado en Tesis y Proyecto de Grado. En tal sentido, estoy a la disposición para colaborar con la revista como árbitro de artículos.

El contenido de este manuscrito se difunde bajo una Licencia de Creative Commons ReconocimientoNoComercial-Compartirlgual 4.0 Internacional 